\title{
La interacción oral en la enseñanza de idiomas: aportaciones de una investigación sobre interrupciones conversacionales
}

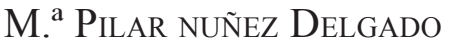 \\ Universidad de Granada \\ Alejandra Hernández Medina \\ Universidad del Bio-Bío, Chile
}

Recibido: 3 noviembre 2010 / Aceptado 22 enero 2010

ISSN: $1697-7467$

\begin{abstract}
RESUMEN: Los planteamientos que para la enseñanza de idiomas ha introducido recientemente el MCERL incorporan un énfasis especial en la destreza de la interacción conversacional. Sin duda, la puesta en práctica de los nuevos enfoques comunicativos, funcionales e interculturales requiere prestar atención a esta tipología textual, cuyo estudio es relativamente escaso tanto en el ámbito de las ciencias del lenguaje como en el de la didáctica de las lenguas, motivos por los cuales nuestro trabajo pretende ofrecer líneas de actuación en este último ámbito, derivadas en parte de los datos de una investigación sobre el intercambio conversacional y el funcionamiento de las interrupciones.
\end{abstract}

Palabras clave: interacción, texto conversacional, interrupciones, competencia oral.

Oral interaction in language teaching: contribution of a research study about conversational interruptions

\begin{abstract}
Recent approaches to second/foreign language teaching introduced by the CEFRL include a special emphasis on conversational interaction. Implementing new communicative, functional and intercultural approaches undoubtedly requires paying attention to this textual typology, whose study is relatively scarce, both in language sciences and language didactics. For this reason, our paper aims to offer some courses of action in language didactics partly derived from a research on conversational exchanges and the role of interruptions.
\end{abstract}

Keywords: interaction, conversational text, interruptions, oral competence.

\section{LA INTERACCIÓN CONVERSACIONAL COMO DESTREZA COMUNICATIVA: CA- RACTERIZACIÓN Y FUNCIONAMIENTO}

En sentido estricto, es decir, si ponemos en relación las dos destrezas psicolingüísticas -comprensivas y expresivas- con los dos códigos usuales y más utilizados -oral y escrito-, no puede considerarse que la interacción sea una destreza distinta, pues forma parte 
de la comunicación oral en tanto consiste en saber alternar los papeles de receptor y emisor con fluidez y eficacia. Sin embargo, al dedicarle un espacio específico, la intención del Marco común europeo de referencia para el aprendizaje, la enseñanza y la evaluación de lenguas (MCERL) del Consejo de Europa (2002) es claramente la de poner de manifiesto la importancia de fomentar esta habilidad, dada la relevancia que sin duda tiene en el mundo actual donde el manejo solvente de la lengua hablada sigue siendo una asignatura pendiente tanto de los sistemas educativos como de la formación de los adultos. El dominio de una lengua, materna o extranjera, no es completo si no se posee esta capacidad en grado suficiente, manifestado en lo que se suele llamar fluidez, pues la interacción es la manifestación más patente de las competencias lingüísticas, sociolingüísticas, pragmáticas e interculturales del usuario y la que ofrece, por tanto, mayor rentabilidad en todas las facetas de la vida personal, académica o laboral de las personas.

No obstante, hemos de admitir que la conversación constituye un género discursivo que es ante todo habla en funcionamiento, una acción social que se construye de forma coordinada entre quienes participan en ella, lo cual explica que, debido a su carácter asistemático e informal, sólo en los últimos cincuenta años se haya convertido en verdadero objeto de atención científica y que, por esto, todavía hoy resulte difícil definirla, estudiarla y utilizarla didácticamente. Actualmente, y desde mediados del pasado siglo, es objeto de atención central de distintas corrientes; así en una línea sociolingüística se sitúan las aportaciones de la Etnografía de la Comunicación, de la Sociología del Lenguaje o del Interaccionismo Simbólico, mientras que el Análisis del Discurso y el Análisis de la Conversación adoptan un enfoque más lingüístico.

La Etnometodología o Análisis de la Conversación se ocupa sobre todo del análisis de la conversación espontánea entendida como actividad social, pues parte de la base de que las actividades cotidianas son métodos que dan sentido a las situaciones. El interés de esta perspectiva consiste en que presenta los actos de comunicación como actividades sociales estructuradas de acuerdo con unas reglas que se adquieren a través de la experiencia interactiva, y en que considera el uso del lenguaje como el mecanismo fundamental que dota de sentido estas actividades. Desde estos presupuestos el sentido se construye socialmente, por cuanto la realidad social se edifica, se recrea, se mantiene y se cambia a través de las interacciones en las que las personas se involucran cada día. Su base teórica la componen cuatro hipótesis principales: la de que la conversación se organiza estructuralmente según ciertas convenciones sociales y que como tal puede ser estudiada; la que sostiene que cada contribución de los participantes es doblemente contextual en tanto, además de estar determinada por el contexto en que se produce, sirve a su vez de contexto de la acción siguiente, con lo que la contextualización es la base que permite a los participantes dar sentido a las acciones; la que, dadas las dos anteriores, rechaza la construcción de teorías previas para el estudio de la conversación y practica un acercamiento rigurosamente empírico en el que nada es rechazado por accidental o relevante que parezca; y, por fin, la que exige estudiar la conversación a partir de muestras reales en situaciones naturales (Cestero, 2000).

En este punto se incluyen también algunas elaboraciones del Interaccionismo Simbólico (o microanálisis sociológico), representado por Goffman (1967), y cuyo postulado fundamental es que las interacciones comunicativas son semejantes a los rituales $-\mathrm{y}$, por 
tanto, están altamente estructuradas- y que la sociedad constituye un orden comunicativo e interpretativo. Los interlocutores que participan en un intercambio comunicativo negocian entre ellos el mantenimiento o el cambio de su imagen de partida ${ }^{1}$.

En uno de los pocos estudios monográficos con que sobre el tema contamos en nuestro país, A. Tusón, (1997: 11) la presenta así2:

La conversación es una de las actividades más típicamente humanas. Es la forma primera y primaria en que se manifiesta, en que existe el lenguaje y hemos de entenderla, además, como una práctica social a través de la cual se expresan y se hacen posibles otras prácticas. A través de las conversaciones nos comportamos como seres sociales: nos relacionamos con las demás personas conversando, tratamos de conseguir nuestros propósitos conversando, rompemos nuestras relaciones conversando o dejando de conversar. Incluso cuando pensamos, en solitario, lo hacemos casi siempre en forma de diálogo.

Mientras López Valero (1996: 119) define la conversación como «la acción y efecto de hablar familiarmente una o varias personas», con lo cual la entiende como un tipo de comunicación que surge, la mayor parte de las veces, de forma espontánea, y que utilizamos para intercambiar conocimientos, sensaciones, emociones, ideas, etc.; para Briz (1996: 32) es el prototipo discursivo de la modalidad coloquial, caracterizada por rasgos tales como la interlocución en presencia, la inmediatez, la toma de turno no determinada y el dinamismo, con alternancia de turnos inmediata. Más precisa es la aportación de Cestero (2000: 19), quien presenta la conversación como una secuencia interactiva de intervenciones, realizadas por interlocutores diferentes de la misma categoría real o funcional, con una organización general determinada no convencionalizada ni planificada y con una organización pormenorizada no predeterminada, producida mediante el funcionamiento de un mecanismo de alternancia de turnos específicos, no controlado o dirigido de forma unilateral, y cuyo objetivo social es, en principio, la comunicación por la comunicación. Por su parte, Gutiérrez (2002) la caracteriza como un conjunto de actos comunicativos en los que dos o más sujetos hablantes intercambian mensajes orales alternando sus funciones de emisor y receptor de forma libre y espontánea en unas coordenadas de simultaneidad espacial y temporal,

Las características que le asignan Sacks, Schegloff y Jefferson (1974) a esta tipología textual son las siguientes: a) el cambio de hablante es recurrente, es decir, la conversación es dialogal; b) no habla más de una persona a la vez; los solapamientos son frecuentes pero breves; c) las transiciones más comunes entre turnos se producen sin intervalos ni solapamientos o con un breve intervalo; d) el orden de los turnos de palabra no es fijo y tampoco su duración, aunque se tiende a cierto equilibrio; e) lo que dicen los hablantes

1 En relación con la conversación uno de sus conceptos destacados es el de posición y sus manifestaciones lingüísticas y no lingüísticas, que son las señales que permiten descubrir cómo la interacción se organiza en diversas secuencias que, a su vez, provienen de la aplicación de determinados marcos o patrones de actuación comunicativa construidos con elementos tanto sociales como cognitivos.

${ }^{2}$ Queda más que justificada la afirmación de López Morales (1999: 18): «No es fácil, aunque a veces lo parezca, saber conversar». 
no se ha especificado previamente ni tampoco la distribución de los turnos de palabra; f) el número de hablantes puede variar; g) el discurso puede ser continuo o discontinuo; h) existen técnicas para la distribución de los turnos; i) se utilizan diferentes unidades formales de construcción de los turnos (una palabra, una frase...), y j) existen mecanismos para reparar los errores o las transgresiones en la toma de la palabra.

Respecto a la estructura que presenta el discurso conversacional, un temprano trabajo de Van Dijk (1978: 55) distingue la macroestructura, estructura global que corresponde a un macronivel en el que la conversación queda organizada como un todo y en la que se distinguen fases de preparación, apertura, orientación de la conversación, determinación del objeto de la conversación y terminación; y la microestructura, que corresponde a un micronivel en el que aparecen los enunciados individuales y sus respectivas relaciones. Sin embargo, no es fácil concretar cuáles son las unidades de la conversación, si bien se puede afirmar que se construye mediante alternancia de turnos emitidos por diferentes participantes, con lo que se perfila una unidad básica, el turno, o periodo de tiempo que comienza cuando una persona empieza a hablar o a comunicar y concluye cuando deja de hacerlo, y una acción recurrente, la alternancia (Cestero, 2000).

Centrándonos en la configuración de turnos, nos interesa resaltar que ésta no es casual, está organizada: opera puntualmente, se controla de forma intencional, la administran los propios participantes y es sensible a las intenciones del receptor. Los mecanismos básicos por los que se rige el cambio de turno son dos: la heteroselección, que se produce cuando quien está usando la palabra selecciona al siguiente hablante; y la autoselección, cuando una de las personas presentes empieza a hablar sin que quien tiene la palabra la haya seleccionado. Estos mecanismos funcionan relativamente bien porque los interlocutores reconocen lo que se denominan lugares apropiados para la transición (LAT), que pueden estar señalados por una pregunta, un gesto o una entonación descendente seguida de pausa.

El principio que estructura la interacción es el de cooperación (Grice, 1997), que consiste en la negociación de significados mediante el uso constante de estrategias de comprensión y expresión. A este principio general se unen otras estrategias de tipo cognitivo-discursivo ciertamente complejas «[...] que suponen controlar la colaboración y la interacción en acciones tales como tomar el turno de palabra y cederlo, formular el tema y establecer un enfoque, proponer y evaluar las soluciones, recapitular y resumir lo dicho y mediar en un conflicto» (MCERL, 2002: 75). Sin embargo, cuando conversamos no solemos tener en cuenta las máximas señaladas por Grice (cantidad, calidad, relevancia y modalidad), porque optamos por mantener nuestras relaciones sociales en buenos términos antes que por ser comunicadores eficaces, de aquí que nuestras intervenciones conversacionales se extiendan más de lo necesario y pequen, en ocasiones, de poco veraces. También es habitual que nos expresamos con poca claridad, que insertemos elementos poco pertinentes o que no respetemos los turnos de palabra e interrumpamos adoptando una posición de control o dominio ${ }^{3}$. Vistas así las cosas, quizás la interrupción

3 Tanto desde la perspectiva lingüística como didáctica cabe cuestionarse, por ejemplo, con qué objetivos un hablante interrumpe al otro, si un hombre interrumpe de la misma forma y con los mismos propósitos que una mujer o si una persona mayor lo hará igual que una de mediana edad. 
no deba ser considerada como una trasgresión a las normas establecidas en la conversación, sino que probablemente sea una estrategia ya validada por el uso, susceptible de ser enseñada y aprendida, y de enorme rentabilidad en la eficacia comunicativa y en la construcción y preservación de nuestra imagen y nuestro territorio (Brown y Levinson, 1987).

La interrupción es la manifestación de acciones que impiden que la participación de un hablante se inicie, avance o concluya. Tales acciones serían provocadas de manera voluntaria o involuntaria de acuerdo con las intenciones del hablante. La primera se explicaría por una falta de atención de los hablantes quienes no atenderían conscientemente las indicaciones de sus interlocutores y, por tanto, no prestarían atención a las marcas propias del turno en curso; la segunda se produce cuando los interlocutores no interpretan bien o no son capaces de reconocer el valor significativo de las marcas que se emiten en el turno en marcha. Gallardo (1993: 10) distingue, por su parte, entre interrupciones competitivas, solapamiento que se inicia durante el desarrollo de otra intervención que trata de imponerse, e interrupciones colaborativas, que intentan terminar el turno con las mismas palabras (y dichas a la vez) que el hablante.

Desde el punto de vista didáctico nos parece importante insistir en que los turnos de palabra y las interrupciones tienen una importancia enorme en la comunicación -y, en consecuencia, en la enseñanza de las lenguas-, pues incluso nos permiten formarnos juicios sobre los demás basados en la forma en que se asignan, se pierden o se ceden los turnos, y en la fluidez con que se producen los intercambios. La falta de eficacia en la alternancia de turnos puede hacer que consideremos a alguien grosero -si interrumpe constantemente-, o dominante -si no cede el turno lo suficiente-, o frustrante -si no hace aportaciones destacables. La observación de intercambios conversacionales de hablantes del español de Chile que ha constituido nuestra investigación corrobora estas afirmaciones y permite extraer algunas implicaciones de utilidad para la enseñanza-aprendizaje de lenguas.

\section{Aportaciones de UnA INVESTIGACIÓn SOBRE INTERRUPCIONES CONVERSA- CIONALES}

De forma muy esquemática se exponen a continuación los elementos y datos principales de la investigación realizada, pues nos interesan más las implicaciones didácticas de los resultados que la presentación detallada de éstos y del proceso seguido, que se vinculan más con el ámbito de la Sociolingüística.

\subsection{Objetivos}

Se trata de un estudio de corte fundamentalmente cuantitativo sobre las estrategias conversacionales en el español de Chile cuyos objetivos específicos se centran en (a) determinar los propósitos y motivaciones que conducen a los hablantes a interrumpir a su interlocutor, y (b) comprobar si existen correlaciones entre la edad y el sexo de los hablantes y los propósitos y motivaciones que les impulsan a interrumpir. 


\subsection{Muestra}

Se trabajó con 58 entrevistas orales realizadas en dos localidades del norte y sur de Chile (Copiapó y Rancagua, respectivamente) elegidas por sus características geográficas y socioculturales. Para la búsqueda de informantes se planificó el número de hombres y mujeres (50\% por sexo) que se necesitaba, la cantidad de personas por cada grupo generacional y los niveles socioculturales que se investigarían. Respecto a los tipos de muestreo utilizados, se recurrió a los de tipo estratificado al azar, muestreo por cuotas y muestreo intencionado (Moreno, 1990), además de a la técnica de bola de nieve (López Morales, 1994: 60).

Con el propósito de crear un clima propicio para la producción lingüística natural y espontánea del hablante (Silva-Corvalán, 1989) prescindimos absolutamente de pautas que indicasen los tópicos a tratar y se procuró que fueran fluyendo a medida que se avanzaba en la conversación, dependiendo siempre del hablante y sus características. Los temas propuestos por el entrevistador se eligieron pensando en que fuera fácil obtener respuestas y, por tanto, abundantes muestras de lenguaje de los interlocutores y fueron, prioritariamente: la familia, las vacaciones, la educación de los hijos y la reforma educativa, la seguridad ciudadana, el trabajo, los proyectos laborales, los pasatiempos, las zonas turísticas de Chile, la mujer y su doble rol social, el matrimonio, el divorcio y la vida universitaria. El tiempo de grabación de cada conversación-entrevista estuvo en torno a los 30 minutos por sujeto.

\subsection{Variables consideradas}

Se distinguieron variables dependientes e independientes. Las primeras correspondieron a las características demosociales de los individuos (sexo y grupo generacional) y se distribuyeron del modo que sigue:

\begin{tabular}{|c|c|c|c|}
\hline & $\begin{array}{c}\text { Primer grupo } \\
\text { generacional } \\
(18 \text { a 35 años })\end{array}$ & $\begin{array}{c}\text { Segundo grupo } \\
\text { generacional } \\
(36 \text { a } 55 \text { años })\end{array}$ & $\begin{array}{c}\text { Tercer grupo } \\
\text { generacional } \\
(56 \text { años o más })\end{array}$ \\
\hline $\begin{array}{c}\text { Porcentaje } \\
\text { de sujetos }\end{array}$ & $33,9 \%$ & $35,7 \%$ & $30,4 \%$ \\
\hline
\end{tabular}

Como variables independientes se consideraron los propósitos y motivaciones que orientaron las interrupciones.

Para el tratamiento de los datos se utilizó el programa SPSS.14 que permitió, en el marco de una estadística descriptiva, el análisis exploratorio de los datos, determinar los valores de posición y dispersión de los mismos, elaborar tablas de frecuencias, tablas de contingencia, correlaciones, etcétera. 


\subsection{Resultados obtenidos}

\subsubsection{Primer grupo generacional (18-35 años)}

Los datos obtenidos permiten apreciar que los varones jóvenes interrumpen a su interlocutor con diferentes propósitos, a saber, y en orden de mayor a menor frecuencia:

1) Completar una idea que el oyente dejó inconclusa.

2) «Robar la palabra» para ayudar a quien le escucha, que aparentemente ha sufrido una laguna mental que le impide dar con las palabras adecuadas, en una clara intención cooperativa.

3) Dar inicio a una nueva intervención.

4) Completar una anterior participación, desestimando a veces, aportes del interlocutor.

5) Insistir repitiendo la respuesta emitida en la intervención anterior.

6) Reforzar una aserción del interlocutor que, aunque incompleta, es captada perfectamente por el oyente.

7) Responder con rapidez y otorgar una respuesta enfática.

En el caso de las mujeres correspondiente a este primer grupo de edad se observa que se efectúan con los siguientes rasgos característicos ordenados asimismo de mayor a menor frecuencia:

1) Solapamientos a través de los cuales se manifiestan acuerdos.

2) Necesidad de dar inicio a un nuevo turno.

3) Intención de rebatir algún comentario del interlocutor.

4) Solapamientos en los que se busca dar una respuesta rápida y segura.

5) Intención de emitir un punto de vista.

6) Insistencia en reforzar una respuesta mediante solapamientos e intervenciones inmediatas.

7) Colaboración con el interlocutor, repitiendo el mismo argumento, pero con otras palabras.

\subsubsection{Segundo grupo generacional (35-55 años)}

Los varones cuyas edades oscilan entre los 36 y 55 años de edad interrumpen orientados, en orden descendente, por los propósitos siguientes:

1) Replicar, solapadamente, una aserción emitida por el interlocutor.

2) Completar una intervención anterior.

3) Reformular la pregunta que se le ha planteado.

4) Responder de manera inmediata.

5) Reforzar la intervención del interlocutor.

6) Completar el enunciado del interlocutor.

7) Manifestar acuerdo a través de una participación solapada.

8) Clarificar algo, o bien, manifestar desacuerdo con el interlocutor.

9) Continuar y completar una participación anterior, desestimando la intervención del interlocutor. 
Cuando las mujeres de estas edades interfieren en la participación del interlocutor lo hacen guiadas por los propósitos siguientes:

1) Completar una idea que ha quedado inacabada.

2) Elaborar una respuesta intensificada.

3) Acotar algo que ha quedado pendiente en su intervención anterior.

4) Iniciar inmediatamente una intervención.

5) Esclarecer o corregir una afirmación del interlocutor.

6) Adelantarse a las palabras del interlocutor.

7) Ratificar, a través de una participación solapada, una afirmación del interlocutor.

8) Corregir al interlocutor mediante una intervención solapada.

9) Apresurarse a responder en una intervención inmediata.

\subsubsection{Tercer grupo generacional (55 años o más)}

En este grupo de edad se aprecia que las interrupciones se llevan a cabo con propósitos, en orden de prioridad, tales como:

1) Completar una participación anterior que ha quedado inacabada.

2) Responder con rapidez a la interrogante planteada por el interlocutor.

3) Refutar alguna afirmación del interlocutor.

4) Afirmar algo o emitir una opinión que luego será intensificada a través de la repetición. Posteriormente se observa un intento por reconducir el tema hacia otros aspectos del mismo.

5) Manifestar acuerdo con el interlocutor.

6) Colaborar con el interlocutor proporcionándole mayor información.

7) Solicitar mayor información.

8) Completar la intervención del interlocutor.

En cuanto a las mujeres mayores de 55 años, podemos señalar que sus interrupciones obedecen, en orden descendente, a los propósitos siguientes:

1) Dar una respuesta rápida, directa y sin mayor elaboración.

2) Manifestar el acuerdo con el interlocutor.

3) Completar intervención anterior, omitiendo al interlocutor.

4) Adelantarse para manifestar desacuerdo con el interlocutor. En este caso, la intervención es intensificada y solapada en un primer momento; posteriormente se trata de una intervención inmediata, y también intensificada por medio de la repetición.

5) Reforzar, en intervención solapada, una aserción hecha en un turno anterior.

6) Esclarecer una pregunta.

7) Rebatir una afirmación del interlocutor.

\subsection{Análisis global de los principales resultados}

En el discurso conversacional coloquial chileno, el mayor número de interrupciones, tanto en hombres como en mujeres, se observa bajo las siguientes circunstancias y/o propósitos: i) adelantarse para dar respuestas rápidas e intensificadas (mujeres en un 29\% 
de los casos y hombres en un 21\%); ii) rebatir los argumentos del interlocutor (ellas en un $26 \%$ y ellos en un 18\%), y iii) completar la propia intervención anterior (mujeres en un $16,2 \%$ y hombres en un $21 \%$ ).

Sin embargo, existen motivaciones para la interrupción que diferencian claramente a los sexos. Así, los hombres suelen colaborar más con su interlocutor, ayudándolo -por ejemplo- a completar enunciados en los que manifiesta dificultades de expresión. Este rasgo se aprecia en un $18 \%$ de los varones mientras que en las mujeres sólo se da en un $3,2 \%$ de los casos. Ellos también se distinguen por reforzar, más que las mujeres, las aserciones del interlocutor, rasgo que se observa en un $11,2 \%$ frente a un $6,4 \%$. Las mujeres, más que los varones, exigen al interlocutor que les proporcione mayor información que les permita continuar avanzando en la conversación. Esto ocurre en un 6,4\%, mientras que los hombres interrumpen con este propósito sólo en un 3,6\%. Una característica que únicamente se observa en mujeres es la interrupción o solapamiento para mostrar acuerdo con el interlocutor $(3,2 \%)$; asimismo otro rasgo que no se aprecia en varones es la interrupción para iniciar una intervención $(6,4 \%)$.

Respecto al modo en que se manifiesta la interrupción en los tres grupos generacionales del estudio, cabe señalar que en todos ellos hay un mayor porcentaje de recurrencia en las refutaciones hechas al interlocutor $(20 \%$ en el primero; $21 \%$ en el segundo, y $23 \%$ en el tercero) y en los adelantamientos para dar respuestas rápidas y en ocasiones intensificadas $(33,3 \%$ en la primera, $21 \%$ en la segunda y $23 \%$ en la tercera).

Existen tipos de interrupción que no se observan en todos los grupos de edad, como sucede en algunas ocasiones en las que el hablante necesita decir algo más para clarificar y reforzar lo dicho en la participación anterior. Este rasgo se aprecia en los grupos segundo y tercero $(5,2 \%$ y $3,8 \%$, respectivamente), pero no en el primero. Otra característica que se observa en dos franjas de edad (primera, con un 6,75\%, y segunda, con un $5,2 \%$ ) es la interrupción motivada por la urgencia de partir con una nueva intervención.

Asimismo, se recogen tipos de interrupciones que particularmente se asocian a un grupo de edad, como es el caso de aquéllas que se realizan para solicitar una mayor información al interlocutor (tercer grupo generacional, 11,5\%); reformular las preguntas recibidas $(5,2 \%$, segundo grupo de edad); y manifestar acuerdos $(4,2 \%$, tercer grupo de edad).

En síntesis, los resultados nos llevan a afirmar, en primer término, que en una conversación de corte coloquial, los hombres interrumpen con fines más colaborativos que las mujeres. En segundo término, cabe señalar que, a medida que se avanza en edad, se tiende a interrumpir más, lo que manifiesta una mayor seguridad y firmeza en los argumentos que se esgrimen, basados seguramente en la experiencia y la práctica de la conversación que se adquieren con los años.

\section{A MOdO DE CONCLUSIÓN: PRINCIPALES IMPLICACIONES DIDÁCTICAS}

Los resultados de nuestra investigación sobre las interrupciones conversacionales permiten afirmar que en todos los grupos de edad y en ambos sexos hay habilidades que pueden ser mejoradas (incorporar un mayor uso de interrupciones colaborativas, gestionar mejor las competitivas para obtener los fines propuestos, etc.) y que la práctica 
consolida estrategias que amplían el rendimiento de las interrupciones en tanto éstas se usan para pedir aclaraciones que facilitan la comprensión o para ganar tiempo y al planificar la propia intervención y, por tanto, desarrollan la capacidad de negociación de significados y el control de la interacción en su conjunto. Resulta evidente, entonces, que la importancia que se reconoce de modo explícito a las habilidades de interacción y al funcionamiento del texto conversacional en la actividad comunicativa afecta directamente al campo de la Didáctica de la Lengua (DL) en tanto que tales habilidades son susceptibles de ser enseñadas y aprendidas y que su dominio da lugar a individuos más competentes ${ }^{4}$.

De este modo, las repercusiones más importantes de estas consideraciones en la enseñanza de idiomas podemos situarlas en los aspectos que se citan a continuación.

1) Este tipo de texto - la conversación- y la destreza que implica -la interaccióndeben constituir el centro de las propuestas de intervención didáctica orientadas al dominio de la expresión y comprensión orales, tanto en lengua materna como en lenguas extranjeras (Tejada, 2007). Los motivos que pueden aducirse son muchos: su peso en la apreciación, por parte de los aprendices y de los oyentes, de que se domina una lengua (Padial y Tapia, 2007); su papel central en el establecimiento, la gestión y hasta la ruptura de relaciones sociales; la importancia en ellas de la fluidez y la espontaneidad, que incluso en situaciones de enseñanza formal acercan el uso lingüístico a contextos reales,... En definitiva, porque lo que más destaca en ellas es la complejidad de elementos que las integran y que implican el manejo de todas las propiedades textuales y de todas las subcompetencias que conforman la comunicativo-lingüística.

2) Para este fin, además de contar con una caracterización lingüística, retórica y pragmática del discurso oral (Nieto, 1995) y de la conversación, es fundamental disponer - para que la transposición didáctica sea viable- de investigaciones abundantes y de análisis rigurosos en los que se establezcan cuáles son las unidades que la componen, cómo funcionan y cuándo y para qué se usan. A partir de estos datos podrán diseñarse las secuencias didácticas de contenidos y actividades encaminadas a que los aprendices logren dominarlas.

3) En el caso de la lengua materna, la observación del manejo que presentan algunos hablantes de la interacción conversacional y de las estrategias para captar y mantener el turno de palabra hasta lograr sus fines, así como del relevante valor comunicativo y social que estos hechos tienen, ha de animar definitivamente a docentes y a didactas a superar las rémoras de la tradición silente que todavía hoy impera en nuestras aulas -falta de materiales, deficiente formación del profesorado en estos aspectos, escasez de programas sistemáticos y de actividades funcionales, papel pasivo del alumno, etc. (M. ${ }^{a}$ P. Núñez, 2003; M. ${ }^{a}$ P. Núñez y E. Romero, 2009)- y avanzar hacia propuestas que sitúen la

${ }^{4}$ La DL que no puede quedar al margen de este hecho, tal y como señalan, apuntando además dos grandes líneas investigación en este sentido, Bigot y Cicurel (2005: 4): Les interactions sont devenues un enjeu majeur de la réflexion didactique d'une part par verbales ce qu'elles apparaissent comme un des principaux vecteurs de l'action conjointe d'enseignement-apprentissage et d'autre part parce qu'elles constituent désormais un objet d'apprentissage à part entière. 
comunicación oral en parámetros proporcionales a la frecuencia de uso y a la importancia que ésta tiene en todos los ámbitos (social, personal, académico, profesional).

4) Si nos situamos en el terreno de la enseñanza de idiomas extranjeros, aún es más evidente que el logro de la fluidez en la interacción, es decir, la posibilidad de participación en actos conversacionales sin graves dificultades para la expresión y la comprensión, es lo que los aprendices suelen equiparar a «saber hablar» una lengua. Debemos tener presente asimismo que en el aprendizaje de idiomas el conocimiento lingüístico no es suficiente para considerar a un hablante competente porque faltan, al menos, dos componentes fundamentales: el pragmático y el estratégico. Es necesario, sobre todo en la conversación, saber cuándo y cómo interrumpir, en qué contextos, cuándo es pragmáticamente adecuado hacerlo, qué estrategias de reparación se pueden utilizar, o saber captar por qué un hablante interrumpe y con qué propósitos. Si a esto añadimos que los aspectos rituales de la conversación son culturales y, por lo tanto, específicos para cada idioma, el conocimiento de los turnos y de los mecanismos de interrupción tiene que formar parte a fortiori de su enseñanza en el marco de lo que algunos autores como Byram (2007) proponen denominar competencia comunicativa intercultural porque incluye conocimientos, habilidades y actitudes en relación con la cultura o culturas de la(s) lengua(s) que se aprende, sensibilidad en la valoración de las diferencias, así como capacidad para mediar entre miembros de culturas distintas 5 .

5) El desarrollo comunicativo requiere el dominio de la lengua oral y de la lengua escrita y, por lo tanto, una actuación didáctica basada en la integración de destrezas. Las investigaciones realizadas indican que el lenguaje hablado se constituye en una base indiscutible para la enseñanza de la escritura, puesto que ambos utilizan habilidades similares (Shahanan, 2006); la interconexión de las características comunes del habla y de la escritura nos encamina hacia un concepto de aula interactiva que ayuda a gestionar de manera provechosa los procesos de escritura (Constanzo, 2009) ${ }^{6}$.

Los estudios que analizan la relación entre lenguaje oral y escritura en lengua materna han demostrado una clara y consistente conexión entre inteligencia verbal y escritura, y han proporcionado suficiente evidencia de que ambas formas de lenguaje utilizan un conjunto similar de habilidades, incluyendo la memoria de trabajo, la cohesión lingüística y el conocimiento morfológico. A este respecto, un trabajo de Weissberg (2006) examina las formas en que el lenguaje oral y escrito interactúan para los aprendices de segundas lenguas o lenguas extranjeras y describe una aproximación general a la enseñanza de éstas basada en el uso del diálogo en un triple plano -diálogo entre estudiantes y profesor, diálogo

5 Este concepto permite entender que, junto con la destreza de interacción, el MCERL añada una sexta, la mediación.

${ }^{6}$ De manera particular, la escritura parece recurrir al lenguaje oral en el desarrollo de la cohesión; sin embargo, se ha descubierto que la escritura también tiene un impacto en lenguaje oral, por los menos en las formas que se desarrollan de manera tardía como lo son los morfemas, donde la escritura puede hacer que ciertas características del lenguaje se hagan más notorias para el aprendiz. 
entre los mismos estudiantes y diálogo en las propias mentes de los estudiantes de composición escrita- y en cuatro principios: a) las clases de lenguaje más efectivas son aquellas que son verdaderamente comunicativas, significativas y relevantes para los aprendices; b) el uso del lenguaje comunicativo envuelve a personas trabajando juntas para intercambiar información, negociar significados y realizar tareas; c) el aprendizaje de la lengua en el aula es, por naturaleza, una actividad social, de manera que la interacción no es un precursor o una condición para el aprendizaje de la lengua sino una forma en sí misma para su aprendizaje, y d) la interacción social proporciona un contexto ideal para llegar a dominar complejas destrezas cognitivas, entre ellas la escritura ${ }^{7}$, que por su propia naturaleza es una actividad metalingüística (Ong, 1987).

6) Otra dimensión del lenguaje hablado que ha de tenerse muy presente es su doble carácter de contenido educativo y de vehículo de esa misma educación. Es objetivo y contenido, pero también instrumento de comunicación en el aula (Hatch, 1992), y por eso resulta crucial que todo el profesorado se involucre en la tarea de mejora de la interacción oral: de nada servirá trabajar la competencia discursiva oral tres o cuatro horas a la semana en las clases de lenguas y obviarla o no darle su merecida importancia el resto del tiempo y en todas las materias. Este abordaje del lenguaje como herramienta para la gestión de la convivencia y de los procesos de enseñanza-aprendizaje en las aulas, de modo que desde todos los ámbitos de uso se contribuya al desarrollo de la competencia comunicativa de los estudiantes, es el pilar básico de las propuestas metodológicas del llamado Currículum Integrado de las Lenguas o de los enfoques basados en la integración de lenguaje y contenidos (Madrid y García Sánchez, 2001) que hoy se apoyan decididamente desde la administraciones educativas (Junta de Andalucía, 2007) como medidas consustanciales a la pretensión de formar los ciudadanos competentes que demanda la sociedad del conocimiento y que, en consecuencia, busca la educación institucional.

7) Por último, y por ofrecer pautas didácticas que, además de orientar la programación de la educación lingüística, sean directamente aplicables en la práctica, queremos presentar a modo de esquema de actuación una interesante aportación de Hymes (1972). Se trata de su conocida caracterización de las unidades estructurales del hablar como actividades de interacción social a través de los elementos que las componen y cuyas iniciales corresponden en inglés a la palabra speaking (Situation, Participants, Ends, Acts sequences, Key, Instrumentalities, Norms y Genre). La implementación de secuencias didácticas a modo de ciclos que vayan constantemente a) del uso a b) la práctica sistemática graduada en amplitud y dificultad y, c) a la reflexión, puede basarse en estos elementos para fijar a través de ellos los rasgos pragmáticos, retóricos, lingüísticos, etc. de la interacción oral y lograr la consolidación de su dominio.

7 De acuerdo con Weissberg (2006), estas cuatro afirmaciones tomadas en conjunto sugieren que la incorporación de la interacción en el aula de escritura es una extensión natural de la enseñanza comunicativa del lenguaje. 
1. Situación o localización espacial, temporal y psicosocial del hecho comunicativo.

2. Participantes: características socioculturales y relación que existe entre ellos.

3. Finalidades u objetivos de la interacción, así como los productos que se obtienen de ella. Metas y productos pueden no coincidir.

4. Secuencia de actos, es decir, la organización y estructura de la interacción, tanto en lo que se refiere al contenido como a la forma en que se estructuran los temas.

5. Clave o tono de la interacción; grado de formalidad o informalidad.

6. Instrumentos. Incluye el canal (audiovisual en este caso), las formas de hablar o repertorio verbal de los participantes, así como los elementos cinésicos y proxémicos, cuyo peso en la conversación es definitivo.

7. Normas de interacción y de interpretación. Las primeras regulan la toma de la palabra; las segundas se refieren a los marcos de referencia compartidos que permiten interpretar adecuadamente tanto lo dicho como lo no dicho.

8. El género, que se refiere al tipo de interacción (conversación espontánea, clase magistral, etc.), y que se organiza en cada caso en secuencias discursivas diversas (expositivas, narrativas, dialogadas, etc.).

En suma, lo que interesa resaltar ante todo es que la interacción conversacional debe constituir el centro de las propuestas de intervención didáctica orientadas al dominio de la expresión y comprensión orales en particular y de la competencia comunicativa en general. Y esto no sólo por la frecuencia de su uso, sino porque lo que más destaca en ella es la construcción conjunta y progresiva de significados comunicativos a partir de secuencias aparentemente desorganizadas, pero dotadas de coherencia interna para los interlocutores, cuyos intereses están enlazados entre sí por la continuidad temática, las normas del sistema y los referentes culturales. De este modo, para que pueda diseñarse y llevarse a cabo una verdadera didáctica de la interacción que dé cumplimiento a lo recomendado en MCERL es fundamental disponer de análisis de la misma en los que se establezcan cuáles son las unidades que la componen y cómo funcionan, para -a partir de ahí- diseñar secuencias graduadas de objetivos, contenidos y actividades encaminados a que los aprendices logren dominarlas como parte esencial de su competencia y su actuación comunicativas en la lengua materna y en las extranjeras.

\section{REFERENCIAS BIBLIOGRÁFICAS}

Bigot, V. y Cicurel, F. (2005). «Les interactions en classe : contextes, ressources, enjeux», Le français dans le monde, numéro spécial : 4-6.

Briz, A. (1996). El español coloquial: situación y uso. Madrid: Arco/Libros.

Brown, P. y Levinson, S. (1987). Politeness. Some universals of language usage. Cambridge: U.P.

Cestero, A. M. ${ }^{a}$ (2000). Los turnos de apoyo conversacionales. Cádiz: Servicio de Publicaciones de la Universidad de Cádiz.

Constanzo, E. (2009). «Towards the development of a global communicative competence: the integration of oral and written skills in teaching and learning a foreign language», en Porta Linguarum, 12: 107-116. 
Grice, P. (1997). «Lógica y conversación», en L. M. Valdés Villanueva (ed.), La búsqueda de significado. Madrid: Tecnos, 524-543.

Gallardo, B. (1993). «La transición entre turnos conversacionales: silencios, interrupciones y solapamientos», en Contextos, XI /21-22: 189-220.

Goffman, E. (1967[1970]). Ritual de la interacción. Ensayos sobre el comportamiento cara a cara. Buenos Aires: Tiempo Contemporáneo.

Gutiérrez, S. (2002). De pragmático y semántica. Madrid: Arco Libros.

Hatch, E. (1992). Discourse and Language Education. Cambridge: Cambridge University Press. Hymes, D. (1972). «Models of the interaction of language and social life», en J. J. Gumperz y D. Hymes (eds.), Directions in Sociolinguistics: The Ethnography of communication. Holt, Rinehart and Winston: New York: 1986.

Junta de Andalucía (2007). Plan de fomento del plurilingüismo. Una política lingüística para la sociedad andaluza. Sevilla: Consejería de Educación. Disponible en: http:// www.juntadeandalucia.es/averroes/impe/web/portadaEntidad?pag=/contenidos/B/ InnovacionEInvestigacion/ProyectosInnovadores/Plurilinguismo/ Acceso el 25 de octubre de 2010 .

López Morales, H. (1994). Métodos de investigación lingüistica. Salamanca: Colegio de España.

López Morales, H. (1999). «Adquisición de la lengua y cultura lingüística», en A. Romero et alii (eds.), Educación lingüística y literaria en el ámbito escolar. Granada: Grupo Editorial Universitario.

López Valero, A. (1996). «Tipología textual y técnicas de expresión oral», en Lenguaje y Textos 9: $115-131$.

Madrid, D. y García Sánchez, E. (2001). «Content-based Second Language Teaching», en E. García Sánchez (ed.). Present and Future Trends in TEFL. Almería: Secretariado de Publicaciones de la Universidad de Almería, 101-134.

Moreno Fernández, F. (1990). Metodología sociolingüística. Madrid: Gredos.

Ministerio de Educación, Cultura y Deporte (2002). Marco común europeo de referencia para las lenguas: aprendizaje, enseñanza, evaluación. Madrid: MECD/Anaya.

Nieto García, J.M. (1995). Introducción al análisis del discurso hablado. Granada: Servicio de Publicaciones de la Universidad.

Núñez, M. ${ }^{a}$ P. (2003). Didáctica de la comunicación oral. Bases teóricas y orientaciones metodológicas para el desarrollo de la competencia discursiva oral en la educación obligatoria. Granada: Grupo Editorial Universitario.

Núñez, M. ${ }^{a}$ P. y Romero, E. (2009). «Estrategias didácticas para la enseñanza de la lengua oral en la Educación Primaria», en Revista de Educación de la Universidad de Granada, 22 (1): $125-152$.

Ong, W. (1987). Oralidad y escritura. México: FCE.

Padial, R. y Tapia, E. (2007). «The motivation to use oral language in the EFL classroom in ESO and Bachillerato», en Porta Liguarum, 7: 135-151.

Sacks, H., Schegloff, E. y Jefferson, G. (1974). «A simplest systematics for the organization of turn-taking y conversation,» en Language, 50: 696-735.

Shahanan, T. (2006). «Relations among oral language, reading and writing development», en Ch. MacArthur; S. Graham y J. Fitzgerald (eds.). Handbook of writing research. Nueva York, The Guilford Press.

Silva Corvalán, C. (1989). Sociolingüistica: teoría y análisis. Madrid: Alhambra.

Tejada Molina, G. (2007). Enfoque ecléctico y pautas del diseño curricular para la enseñanza del idioma oral. Jaén: Servicio de Publicaciones de la Universidad.

Tusón, A. (1997). Análisis de la conversación. Barcelona: Ariel.

Weissberg, R. (2006). Connecting speaking and writing in second language writing instruction. Ann Arbor: The University of Michigan Press. 